\title{
Dairy performance of Red Sindhi cattle in Pakistan
}

\author{
G. Sarwar ${ }^{1}$ and O. Syrstad ${ }^{2}$ \\ ${ }^{1}$ Directorate of Animal Husbandry, Government of Sindh, Hyderabad, Pakistan \\ ${ }^{2}$ Norwegian Centre for International Agricultural Development, Agricultural University of Nonvay, \\ PO Box 2, 1432 Ass, Norway
}

\section{Introduction}

Red Sindhi is, besides Sahiwal, the most widely known dairy breed of zebu cattle. Originating in Sindh Province, Pakistan, this breed has been widely used in cattle improvement programmes, not only throughout south-east Asia, but on other continents as well. Several of the new breeds of mixed Bos indicusBos taurus ancestry have received part of their genetic material from Red Sindhi.

Most previous studies on the dairy performance of Red Sindhi cattle have been based on data from India. In the present study, data obtained on two government farms located in the home tract of the breed were examined.

\section{Material and methods}

Records on lactation yield, lactation length and length of calving interval were collected and analysed. The data set consisted of 680 lactations by 142 cows, and covered a period of 15 years.

\section{Results}

Overall averages for both herds combined were: lactation yield, $1208 \mathrm{~kg}$; lactation length, 256 days; calving interval, 486 days.

Lactation yield deteriorated dramatically in both herds over the time covered by the data. In one of the herds this deterioration was accompanied by a large increase in length of calving interval, while lactation length remained almost constant. Season of calving had only a minor effect on lactation yield and lactation length. Lactation yield increased (by proportionately about 0.3 ) from first to second parity in one herd, but not in the other. This suggests that parity alone is not a good criterion for correcting lactation records for the effect of age, actual age should also be considered. In both herds length of calving interval tended to decrease as age/parity increased, while parity had no significant effect on lactation length.

Lactation yield and lactation length were closely correlated in both herds. Lactation length was also correlated with length of calving interval, while the association between lactation yield and calving interval was inconsistent.

Estimates of repeatability were low for all traits (range 0.18 to 0.37 ). A lower repeatability would be expected for calving interval than for the other traits studied, as traits associated with reproduction are known to be of low heritability.

\section{Discussion}

A close association between lactation yield and lactation length has been found in many studies on tropical cattle. Some authors have interpreted this as meaning that lactation yield should be corrected for lactation length before the records are used for culling and selection. This overlooks the fact that length of lactation is a trait which is genetically controlled to almost the same extent as lactation yield, and that correction would tend to remove the genetic difference among cows. The optimum use of lactation length for selection purposes is to include it as one of the traits in a selection index. 